\title{
Judging Experimental Evidence on Dynamic Inconsistency
}

\author{
By Charles Sprenger*
}

Models of dynamically inconsistent decision-making are among the most prominent in behavioral economics (Laibson 1997; O'Donoghue and Rabin 1999; Gul and Pesendorfer 2001; Fudenberg and Levine 2006). Such models capture the tensions of temptation and self-control in elegant formulation, delivering intuitive deviations from the standard model of intertemporal choice, and providing novel prescriptions for policymakers. In this brief paper, I attempt to judge the experimental literature on dynamic inconsistency, identifying key challenges and innovations, and providing one view as to how the literature may evolve.

A notably large body of experimental research investigates the predictions of dynamically inconsistent models (for a summary to the early 2000s, see Frederick, Loewenstein, and O'Donoghue 2002). As such, the review provided here cannot be comprehensive. A further limitation in scope is that though I have attempted to explore broadly, my review and judgments may be somewhat tilted toward laboratory, as opposed to field, experiments in this domain.

The core of the experimental literature on dynamic inconsistency has two key features. First, the body of research largely identifies preferences from time-dated monetary choices. Second, experimental designs focus primarily on key predictions of dynamically inconsistent models rather than explicit dynamic inconsistencies. I elaborate on these two points, discussing the challenges they pose for identifying models in question, and recent attempts to rise to these challenges.

\footnotetext{
* Rady School of Management and Department of Economics, University of California San Diego, 9500 Gilman Drive, La Jolla, CA (e-mail: csprenger@ucsd. edu). With thanks to Jim Andreoni, Doug Bernheim, Yoram Halevy, Ted O'Donoghue, and Stephan Meier for helpful conversations leading to this draft.

${ }^{\dagger}$ Go to http://dx.doi.org/10.1257/aer.p20151086 to visit the article page for additional materials and author disclosure statement.
}

\section{Time Dated Monetary Payments}

Time dated monetary payments have been the norm in experimental research on intertemporal choice (Frederick, Loewenstein, and O'Donoghue 2002). Such experiments using choices between sooner and later monetary rewards have, until recently, generated robust evidence in support of dynamically inconsistent models. At least three assumptions are required for such choices to be informative for intertemporal preferences. First, subjects must fail to think of their experimental choices in the context of their external borrowing and lending opportunities. In the presence of arbitrage opportunities, choices over monetary payments should reveal nothing about preferences (Cubitt and Read 2007; Chabris, Laibson, and Schuldt 2008) 1 These arbitrage implications must be assumed away? Second, akin to narrow-bracketing, subjects must hold fixed or ignore their external consumption choices when making experimental decisions. While researchers are able to vary experimental payments, subjects potentially make choices over both these payments and nonexperimental background consumption. It must be assumed that individuals do not adjust their background consumption in response to payment, and that it is sufficiently stable to limit confounding identified preferences. Third, transactions costs and payment reliability must not influence subject choices. Differential transactions costs or payment reliability through time can generate apparent dynamic inconsistencies. As such, it must

\footnotetext{
${ }^{1}$ This point has been thoughtfully taken into account in some studies. For example, Harrison, Lau, and Williams (2002) explicitly account for potential arbitrage in their calculations of individual discount rates by measuring individual borrowing and saving rates and incorporating these values in estimation.

${ }^{2}$ I am aware of only one paper experimentally testing these arbitrage implications, Coller and Williams (1999), who present experimental subjects with a fully articulated arbitrage argument and external interest rate information and document only a small treatment effect.
} 
be assumed that subject responses reflect only their time preferences and not their assessment of experimenter reliability.

Each of these assumptions poses a challenge for experimental identification. If they are not satisfied, then the substantial evidence in favor of dynamically inconsistent models from timedated monetary choices may be confounded. Exploring such a possibility and robustifying the evidence in light of this critique have been topics of recent interest.

First, for arbitrage opportunities, Andreoni and Sprenger (2012a) provide one experimental innovation in this vein. They introduce the Convex Time Budget (CTB), wherein subjects allocate an experimental budget of money across sooner and later dates. One implication of arbitrage is that subject responses should lie primarily at corner solutions, allocating the entire budget to either the sooner or later date depending on the interest rate ${ }^{3}$ The researcher should thus uncover a linear utility function, with sooner and later payments serving as perfect substitutes. This is indeed what Andreoni and Sprenger (2012a) find, with a preponderance of corner solutions and close to linear utility estimates 4 These findings have been reproduced in several samples with money (Andreoni and Sprenger 2012b; Augenblick, Niederle, and Sprenger 2013; Andreoni, Kuhn, and Sprenger 2013), and may hint at the presence of such arbitraging behavior. Interestingly, with larger relative stakes in developing country environments, Giné et al. (2010) show substantially more interior CTB allocations. The prevalence of corner solutions in such CTB studies may be informative for the extent to which monetary discounting studies are subject to arbitrage concerns and hence, can be relied on to identify time preferences.

Second, for external consumption opportunities, a set of projects has recently begun to recognize the importance of background consumption for identifying time preferences.

\footnotetext{
${ }^{3}$ It may be easier to test this implication of arbitrage rather than collect precise information on borrowing and lending opportunities for each subject. However, the combination would be of clear value as even without arbitraging the experiment a subject with linear preference would exhibit only corner solutions.

${ }^{4}$ Nonetheless an important minority of subjects exhibit interior solutions such that significant utility curvature is found on average.
}

Andersen et al. (2008) provide an initial investigation, estimating time preferences with background consumption fixed at a survey measure of average daily consumption. Andreoni and Sprenger (2012a) demonstrate the sensitivity of identified preferences to changing assumptions on background consumption, indicating that discounting parameters can vary dramatically depending on the level of background consumption assumed 5 Several recent efforts explore empirically the possibility that changing economic situation, and hence changing background consumption, affect estimated time preferences and dynamic inconsistencies. Dean and Sautmann (2014) provide evidence from Mali that expenditure shocks are linked to measured intertemporal preferences and Carvalho, Meier, and Wang (2014) show a clear link between payday timing and hallmarks of dynamic inconsistency. In contrast, Meier and Sprenger (forthcoming) show limited correlations between changes in financial situation and instability in measured preferences. Though more research in this vein is likely necessary, a reading of the literature would suggest a clear possibility for background consumption, in practice, to present a confound for identifying time preferences and dynamic inconsistency.

Third, for payment reliability, a valid question is whether subjects do indeed believe that all intertemporal payments will be received with equal probability. This point was originally raised by Thaler (1981, p. 207) who, when considering the possibility of using incentivized monetary payments in intertemporal choice experiments noted "Real money experiments would be interesting but seem to present enormous tactical problems. (Would subjects believe they would get paid in five years?)" Thaler's suspicion has been validated in recent work, demonstrating that when transactions costs and payment reliability are closely controlled, dynamic inconsistency is quite limited on aggregate (Andreoni and Sprenger 2012a; Giné et

\footnotetext{
${ }^{5}$ The sensitivity analysis provided by Andreoni and Sprenger (2012a) is conducted with the maintained assumption of stationary background consumption. They show the level of discounting and utility function curvature vary dramatically with choice of level, but that estimates of quasi-hyperbolic discounting parameters are relatively stable. If one relinquished stationarity in background consumption, estimates of quasi-hyperbolicity would also likely be sensitive.
} 
al. 2010; Andreoni, Kuhn, and Sprenger 2013; Andersen et al. 2012; Augenblick, Niederle, and Sprenger 2013; Carvalho, Meier, and Wang 2014). Further, when payment risk is added in an experimentally controlled way, nonexpected utility risk preferences deliver data patterns associated with those of dynamic inconsistency (Andreoni and Sprenger 2012b). This indicates that researchers should be particularly concerned with maximizing payment reliability as findings of inconsistency may well be confounded by treatment of uncertainty.

Given the challenges inherent to experiments with time dated monetary payments, interest has turned to identifying dynamically inconsistency using consumption itself. On relatively short time scales of a few minutes, Solnick et al. (1980) document dynamic inconsistency in choices over irritating noises, and McClure et al. (2007); Brown, Chua, and Camerer (2009) document hallmarks of dynamic inconsistency in beverage choices. Such efforts put precise time stamps on consumption and avoid issues related to risk, background consumption, and arbitrage. However, one may worry that the time-scales are too short to be predictive for economically relevant behaviors. At a larger time interval of a week or more, Read and Van Leeuwen (1998) identify dynamic inconsistency in the surprise reallocation of snack foods, Read, Loewenstein, and Kalyanaraman (1999) identify inconsistencies in "highbrow" and "lowbrow" movie choices, Sayman and Onculer (2009) document inconsistencies in cafe rewards choices (denominated in croissants), Augenblick, Niederle, and Sprenger (2013) document dynamic inconsistencies in effort choices, Kaur, Kremer, and Mullainathan (2014) demonstrate hallmarks of dynamic inconsistency in the money/effort trade-offs of data workers, and Carvalho, Meier, and Wang (2014) demonstrate hallmarks of dynamic inconsistency in the timing of completing survey questions. Both Augenblick, Niederle, and Sprenger (2013) and Carvalho, Meier, and Wang (2014) contrast the extent of dynamic inconsistency elicited via money and consumption, showing limited inconsistencies for money and substantially greater inconsistencies in consumption. Research with direct consumption has shown compelling support for dynamically inconsistent models. However, care should be taken in interpreting this evidence as some of the issues that plague monetary discounting experiments may well be present in these experiments, too.

\section{Hallmarks of Dynamic Inconsistency}

Clear identification of dynamic inconsistency relies on subjects choosing between rewards at time $t$ and time $t+k$ at two points in time, once at time $s<t$ and once at time $t$. Disagreement in these choices is evidence of dynamic inconsistency.

Interestingly, much of the conducted laboratory research relies on experimental tests of changing patience, rather than dynamic inconsistency itself. Two forms of experimental tasks have been popularized. The first form asks subjects to choose between a smaller, sooner reward at time 0 and a larger, later reward at time $k$. Subjects are also asked at time 0 the same question with times $t>0$ and $t+k$. Preferring the smaller, sooner reward in one question and preferring the larger, later reward in another is taken as evidence of changing patience (see, for example Coller and Williams 1999; Ashraf et al. 2006; Meier and Sprenger 2010). The second form uses two delay lengths, $k$ and $k^{\prime}$ and identifies indifference between a smaller, sooner reward at time 0 and larger later rewards at times $k$ and $k^{\prime}$. The researcher examines whether the implied discount rates "paste" together in the manner implied by exponential discounting (see, for example, Kirby, Petry, and Bickel 1999; Giordano et al. 2002).

Though evidence of changing patience may imply a violation of the standard model of exponential discounting and corresponds to predictions of models of dynamic inconsistency, such data patterns could be generated by dynamically consistent models. Subjects with time-dependent, but dynamically consistent, discounting parameters could well deliver the above-noted data patterns. This should be viewed as a critical shortcoming of the experimental literature to date: hallmarks of dynamic inconsistency, as opposed to true dynamic inconsistencies themselves, comprise the body of the literature.

Relatively few studies provide the longitudinal tests necessary to truly identify dynamic inconsistency. This point is noted by Halevy (2012) and Sayman and Onculer (2009), the latter of which identifies only three prior longitudinal studies of time inconsistency: Ainslie and 
Haendel (1983) for monetary choices within heroin-addicted subjects; Read, Loewenstein, and Kalyanaraman (1999) for "highbrow" and "lowbrow" movies between subjects; and Read and Van Leeuwen (1998) for snack choices within subjects. Another early contribution is Solnick et al. (1980). Recent experimental advances with longitudinal designs include Sayman and Onculer (2009) for cafe rewards and money; Halevy (2012) for money; Giné et al. (2010) for money; Augenblick, Niederle, and Sprenger (2013) for effort and money; and Duflo, Kremer, and Robinson (2011) for fertilizer purchase. Critical among these contributions are Giné et al. (2010) and Halevy (2012) who show connections (or lack thereof) between changing patience and true dynamic inconsistencies.

Another path by which hallmarks of dynamic inconsistency are explored is the investigation of commitment demand. Under both temptation models (Gul and Pesendorfer 2001; Fudenberg and Levine 2006) and quasi hyperbolic discounting models with sophistication (Laibson 1997; O'Donoghue and Rabin 1999, 2001) dynamically inconsistent individuals should value commitment. One critical contribution in this vein is Ariely and Wertenbroch (2002), who document commitment demand in the form of meaningful, costly deadlines. Though compelling, this, as well, should be viewed as a prediction of dynamic inconsistency, as opposed to dynamic inconsistency itself. Recent advances have provided links between changing patience or dynamic inconsistency and commitment demand (Ashraf, Karlan, and Yin 2006; Kaur, Kremer, and Mullainathan 2014; Augenblick, Niederle, and Sprenger 2013). These findings limit the set of alternative explanations for either behavior and point compellingly toward models of dynamic inconsistency. Importantly, however, across exercises, the correlation can be low. For example, in Augenblick, Niederle, and Sprenger (2013) measures of dynamic inconsistency explain only about 5 percent of the variation in commitment demand.

\section{A Future Perspective}

In this brief review of the experimental literature on dynamic inconsistency, two points rise to prominence. First, the importance of investigating true dynamic inconsistencies. And second, the need to ensure that assumptions required for plausibly identifying preferences are satisfied.

There are many ways in which the experimental literature on dynamic inconsistency may evolve. I note two potential avenues. First, though monetary discounting experiments suffer from clear confounds and have been called into question recently, the resulting parameter estimates at times link closely to relevant realworld behaviors (see, e.g., Meier and Sprenger 2010, 2012). These findings suggest that monetary measures may indeed capture an element of preferences in some contexts. As such, a valuable research question may be "Who treats money like consumption, and when?" Second, only a small body of literature correlates dynamic inconsistency to commitment demand. Such a correlation is critical for evaluating and discerning between models of dynamic inconsistency. A key input to such exercises is the relationship between behavior (dynamic inconsistency) and beliefs (sophistication). To date little is known empirically about the dimensions of this relationship except that it is likely weakly positive in the few observed cases. Critical contributions remain for tracing out this relationship as the key policy prescription for dynamically inconsistent models rests on whether individuals with inconsistent preferences recognize their inconsistencies.

\section{REFERENCES}

Ainslie, George, and Varda Haendel. 1983. "The Motives of the Will." In Etiologic Aspects of Alcohol and Drug Abuse, edited by E. Gottheil, K. A. Druley, T. E. Skodola, and H. Waxman, 119-40. Springfield: Charles C. Thomas.

-Ariely, Dan, and Klaus Wertenbroch. 2002. "Procrastination, Deadlines, and Performance: Self-Control by Precommitment." Psychologial Science 13 (3): 219-24.

-Andersen, Steffen, Glenn W. Harrison, Morten I. Lau, and Elisabet E. Rutström. 2008. "Eliciting Risk and Time Preferences." Econometrica 76 (3): 583-618.

Andersen, Steffen, Glenn W. Harrison, Morten I. Lau, and Elisabet E. Rutström. 2012. "Discounting Behavior: A Reconsideration." Unpublished.

-Andreoni, James, and Charles Sprenger. 2012a. "Estimating Time Preferences from Convex 
Budgets." American Economic Review 102 (7): 3333-56.

Andreoni, James, and Charles Sprenger. 2012b. "Risk Preferences Are Not Time Preferences." American Economic Review 102 (7): 3357-76.

Andreoni, James, Michael Kuhn, and Charles Sprenger. 2013. "On Measuring Time Preferences." National Bureau of Economic Research Working Paper 19392.

-Ashraf, Nava, Dean Karlan, and Wesley Yin. 2006. "Tying Odysseus to the Mast: Evidence from a Commitment Savings Product in the Philippines." Quarterly Journal of Economics 121 (2): 635-72.

Augenblick, Ned, Muriel Niederle, and Charles Sprenger. 2013. "Working Over Time: Dynamic Inconsistency in Real Effort Tasks." National Bureau of Economic Research Working Paper 18734.

- Brown, Alexander L., Zhikang Eric Chua, and Colin F. Camerer. 2009. "Learning and Visceral Temptation in Dynamic Saving Experiments." Quarterly Journal of Economics 124 (1): 197-231.

Carvalho, Leandro S., Stephan Meier, and Stephanie W. Wang. 2014. "Poverty and Economic Decision-Making: Evidence from Changes in Financial Resources at Payday." Unpublished.

Chabris, Christopher F., David Laibson, and Jonathon P. Schuldt. 2008. "Intertemporal Choice." In The New Palgrave Dictionary of Economics, edited by Steven N. Durlauf and Larry Blume. London: Palgrave Macmillan.

- Coller, Maribeth, and Melonie B. Williams. 1999. "Eliciting Individual Discount Rates." Experimental Economics 2 (2): 107-27.

-Cubitt, Robin P., and Daniel Read. 2007. "Can Intertemporal Choice Experiments Elicit Time Preferences for Consumption?" Experimental Economics 10 (4): 369-89.

Dean, Mark, and Anja Sautmann. 2014. "Credit Constraints and the Measurement of Time Preferences." Brown University, Department of Economics Working Paper 2014-1.

-Duflo, Esther, Michael Kremer, and Jonathan Robinson. 2011. "Nudging Farmers to Use Fertilizer: Theory and Experimental Evidence from Kenya." American Economic Review 101 (6): 2350-90.

-Frederick, Shane, George Loewenstein, and Ted O'Donoghue. 2002. "Time Discounting and Time Preference: A Critical Review.' Journal of Economic Literature 40 (2): 351-401.
-Fudenberg, Drew, and David K. Levine. 2006. "A Dual-Self Model of Impulse Control." American Economic Review 96 (5): 1449-76.

Giné, Xavier, Jessica Goldberg, Dan Silverman, and Dean Yang. 2010. "Revising Commitments: Time Preference and Time-Inconsistency in the Field." Unpublished.

-Giordano, Louis A., Warren K. Bickel, George Loewenstein, Eric A. Jacobs, Lisa Marsch, and Gary J. Badger. 2002. "Mild opioid deprivation increases the degree that opioid-dependent outpatients discount delayed heroin and money." Psychopharmacology 163 (2): 174-82.

-Gul, Faruk, and Wolfgang Pesendorfer. 2001. "Temptation and Self-Control." Econometrica 69 (6): 1403-35.

Halevy, Yoram. 2012. "Time Consistency: Stationarity and Time Invariance." Vancouver School of Economics Working Paper 201219.

-Harrison, Glenn W., Morten I. Lau, and Melonie B. Williams. 2002. "Estimating Individual Discount Rates in Denmark: A Field Experiment." American Economic Review 92 (5): 1606-17.

Kaur, Supreet, Michael Kremer, and Sendhil Mullainathan. 2014. "Self-Control at Work." Unpublished.

-Kirby, Kris N., Nancy M. Petry, and Warren K. Bickel. 1999. "Heroin Addicts Have Higher Discount Rates for Delayed Rewards Than Non-Drug-Using Controls." Journal of Experimental Psychology: General 128 (1): 78-87.

-Laibson, David. 1997. "Golden Eggs and Hyperbolic Discounting." Quarterly Journal of Economics 112 (2): 443-77.

- McClure, Samuel, David Laibson, George Loewenstein, and Jonathan Cohen. 2007. "Time Discounting for Primary Rewards." Journal of Neuroscience 27 (21): 5796-804.

-Meier, Stephan, and Charles Sprenger. 2010. "Present-Biased Preferences and Credit Card Borrowing." American Economic Journal: Applied Economics 2 (1): 193-210.

- Meier, Stephan, and Charles Sprenger. 2012. "Time Discounting Predicts Credit worthiness." Psychological Science 23 (1): 56-8.

Meier, Stephan, and Charles Sprenger. Forthcoming. "Temporal Stability of Time Preferences." Review of Economics and Statistics.

O'Donoghue, Ted, and Matthew Rabin. 1999. "Doing It Now or Later." American Economic Review 89 (1): 103-24. 
O'Donoghue, Ted, and Matthew Rabin. 2001. "Choice and Procrastination." Quarterly Journal of Economics 116 (1): 121-60.

- Read, Daniel, and Barbara van Leeuwen. 1998. "Predicting Hunger: The Effects of Appetite and Delay on Choice." Organizational Behavior and Human Decision Processes 76 (2): 189-205.

- Read, Daniel, George Loewenstein, and Shobana Kalyanaraman. 1999."Mixing Virtue and Vice: Combining the Immediacy Effect and the Diversification Heuristic." Journal of
Behavioral Decision Making 12 (4): 257-73.

-Sayman, Serdar, and Ayse Onculer. 2009. "An Investigation of Time Inconsistency." Management Science 55 (3): 470-82.

-Solnick, Jay V., Catherine H. Kannenberg, David E. Eckerman, and Marcus B. Waller. 1980. "An Experimental Analysis of Impulsivity and Impulse Control in Humans." Learning and Motivation 11 (1): 61-77.

-Thaler, Richard H. 1981. "Some Empirical Evidence on Dynamic Inconsistency." Economics Letters 8 (3): 201-07. 


\section{This article has been cited by:}

1. Mario J. Rizzo, Glen Whitman. Escaping Paternalism 22, . [Crossref]

2. Pradeep Kumar, Shashi Kant. 2019. Endogenous time preferences of forest goods and communitybased forest management. Ecological Economics 163, 205-214. [Crossref]

3. Philipp Chapkovski, Christian Zihlmann. 2019. Introducing otree_tools: A powerful package to provide process data for attention, multitasking behavior and effort through tracking focus. Journal of Bebavioral and Experimental Finance 23, 75-83. [Crossref]

4. Stephen L. Cheung. 2019. Eliciting utility curvature in time preference. Experimental Economics 59. . [Crossref]

5. T Le Cotty, E Maître d'Hôtel, R Soubeyran, J Subervie. 2019. Inventory Credit as a Commitment Device to Save Grain Until the Hunger Season. American Journal of Agricultural Economics 101:4, 1115-1139. [Crossref]

6. Sally Sadoff, Anya Samek, Charles Sprenger. 2019. Dynamic Inconsistency in Food Choice: Experimental Evidence from Two Food Deserts. The Review of Economic Studies 105. . [Crossref]

7. Leonhard K. Lades, Wilhelm Hofmann. 2019. Temptation, self-control, and inter-temporal choice. Journal of Bioeconomics 21:1, 47-70. [Crossref]

8. Keith Marzilli Ericson, David Laibson. Intertemporal choice 1-67. [Crossref]

9. Holger Strulik, Timo Trimborn. 2018. Hyperbolic discounting can be good for your health. Journal of Economic Psychology 69, 44-57. [Crossref]

10. Derek Lemoine. 2018. Age-induced acceleration of time: Implications for intertemporal choice. Journal of Economic Behavior \& Organization 153, 143-152. [Crossref]

11. Melanie Lührmann, Marta Serra-Garcia, Joachim Winter. 2018. The Impact of Financial Education on Adolescents' Intertemporal Choices. American Economic Journal: Economic Policy 10:3, 309-332. [Abstract] [View PDF article] [PDF with links]

12. Holger Strulik, Timo Trimborn. 2018. Hyperbolic Discounting Can Be Good for Your Health. SSRN Electronic Journal . [Crossref]

13. Liam Delaney, Leonhard K. Lades. 2017. Present Bias and Everyday Self-Control Failures: A Day Reconstruction Study. Journal of Behavioral Decision Making 30:5, 1157-1167. [Crossref]

14. Christopher Tsoukis, Frédéric Tournemaine, Max Gillman. 2017. Hybrid Exponential-Hyperbolic Discounting and Growth Without Commitment. The Manchester School 85, e45-e74. [Crossref]

15. Wendy Janssens, Berber Kramer, Lisette Swart. 2017. Be patient when measuring hyperbolic discounting: Stationarity, time consistency and time invariance in a field experiment. Journal of Development Economics 126, 77-90. [Crossref]

16. Elisa De Marchi, Vincenzina Caputo, Rodolfo M. Nayga, Alessandro Banterle. 2016. Time preferences and food choices: Evidence from a choice experiment. Food Policy 62, 99-109. [Crossref]

17. Diego Ubfal. 2016. How general are time preferences? Eliciting good-specific discount rates. Journal of Development Economics 118, 150-170. [Crossref]

18. Michael Frakes, Melissa F. Wasserman. 2016. Procrastination in the Workplace: Evidence from the U.S. Patent Office. SSRN Electronic Journal . [Crossref]

19. Derek Lemoine. 2015. Aging and Perspective: Dynamically Consistent Hyperbolic Discounting. SSRN Electronic Journal . [Crossref]

20. Wendy Janssens, Berber Kramer, Lisette Swart. 2015. Be Patient When Measuring Hyperbolic Discounting: Stationarity, Time Consistency and Time Invariance in a Field Experiment. SSRN Electronic Journal . [Crossref] 